06

\title{
Влияние атомарной структуры базисных плоскостей на межплоскостное расстояние в пиролитических углеродных материалах
}

\author{
(C) Н.И. Боргардт ${ }^{1}$, А.С. Приходько ${ }^{1}$, M. Seibt ${ }^{2}$ \\ ${ }^{1}$ Национальный исследовательский университет „МИЭТ“, \\ Москва, Зеленоград, Россия \\ 2 4-й Физический институт Геттингенского университета, \\ Геттинген, Германия \\ E-mail: lemi@miee.ru
}

Поступило в Редакцию 11 апреля 2016 г.

Атомарная структура углеродных материалов исследована на примере пироуглерода и углеситалла с применением метода реконструкции волновой функции в просвечивающей электронной микроскопии. Показано, что цифровая обработка распределений фаз этих функций позволяет находить среднее расстояние между базисными плоскостями. Используя метод молекулярной динамики для формирования тестовых структур и получая для них расчетные распределения фазы, количественно выявлено влияние обеднения базисных плоскостей атомами углерода на межплоскостное расстояние в пироуглеродных материалах.

Искусственные углеродные материалы, в том числе пироуглерод и углеситалл, благодаря уникальным физико-химическим свойствам все чаще находят применение в различных технических приложениях [1], включая протезирование в медицине [2]. Эти материалы образуются в результате термического разложения углеродосодержащих газов [3], а в случае углеситалла - с добавлением в них хлорида бора [2]. 
Для турбостратной углеродной фазы, из которой состоит пироуглерод и в основном углеситалл, дополнительно включающий в себя частицы карбида бора [4], расстояние между базисными плоскостями (002) может варьироваться от 0.34 до $0.38 \mathrm{~nm}$ [5].

Высокоразрешающая электронная микроскопия (ВРЭМ), позволяющая изучать структуру материалов с атомным разрешением, широко используется для исследования пироуглеродных материалов [5-8]. В частности, в [6] на основе высокоразрешающих микрофотографий проводилась реконструкция атомарной структуры пироуглерода с применением реверсивного метода Монте-Карло и молекулярной динамики (МД). Однако зависимость контраста на микрофотографиях от передаточной функции микроскопа и толщины образца существенным образом усложняет корректную идентификацию атомных расположений.

В $[9,10]$ было показано, что для изучения турбостратной структуры пироуглерода эффективно использовать двумерное распределение фазы (фазовую карту) волновой функции электрона, восстановленной на основе дефокусной серии ВРЭМ-микрофотографий.

В настоящей работе фазовые карты, полученные для пироуглерода и углеситалла, использовались для формирования с применением метода МД тестовых углеродных структур, с помощью которых выявлялось влияние относительных разворотов базисных плоскостей и их обеднения атомами углерода на величину среднего межплоскостного расстояния.

Для исследования атомарного строения турбостратной углеродной фазы для тонких фольг пироуглерода и углеситалла в просвечивающем электронном микроскопе Philips CM-200-UT-FEG при ускоряющем напряжении $200 \mathrm{kV}$ были получены дефокусные серии из 10 ВРЭМ-микрофотографий. Они формировались с шагом дефокусировки объективной линзы $3.5 \mathrm{~nm}$ в окрестности изображения, соответствующего дефокусировке Шерцера $\xi_{S c h}=-38 \mathrm{~nm}$. На рис. $1, a$ схематически показана соответствующая полученным микрофотографиям ориентация базисных углеродных плоскостей относительно электронного пучка, а на рис. $1, b$ приведена одна из них. Контраст на таких микрофотографиях существенным образом зависит от дефокусировки объективной линзы. На изображениях базисных плоскостей турбостратной фазы могут возникать разрывы и раздвоения, как в выделенной пунктиром области на рис. $1, b$. Кроме того, на микрофотографиях могут выявляться области, например, как отмеченная сплошным контуром на 
$a$

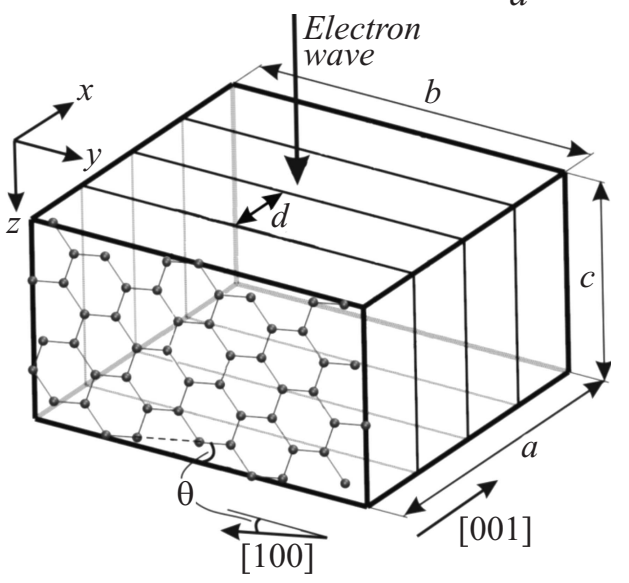

$b$

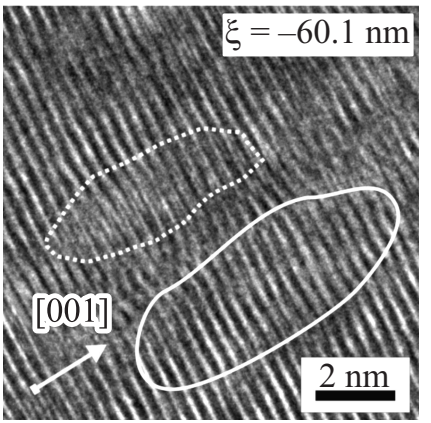

Рис. 1. Схематическое представление ячейки тестовой углеродной структуры $(a)$ и типичное высокоразрешающее изображение турбостратной углеродной фазы $(b)$ при дефокусировке объективной линзы $\xi=-60.1 \mathrm{~nm}$. Сплошным контуром показан один из доменов, выявляемых на изображении базисных плоскостей, пунктирной линией отмечена область, в которой видны неоднородности контраста базисных плоскостей.

рис. $1, b$, которые могли бы свидетельствовать о доменной структуре материала, однако положение подобных областей изменяется при дефокусировке.

По сравнению с высокоразрешающими микрофотографиями фазовая карта $\varphi(x, y)$ имеет существенное преимущество для анализа атомных расположений в пироуглеродных материалах, так как значение фаз на ней практически пропорционально спроецированному вдоль электронного пучка потенциалу образца вплоть до его толщин, близких к $20 \mathrm{~nm}$ [10]. Для нахождения фазовых карт на основе экспериментальных микрофотографий использовался алгоритм итеративного вычисления волновой функции электрона [11], реализованный в виде комплекса программ в компьютерной среде MatLab. Поскольку фаза волновой функции определяется с точностью до константы, то ее значения нормировались с использованием данных, полученных при моделировании тестовых структур.

$1^{*}$ Письма в ЖТФ, 2016, том 42, вып. 23 
$a$

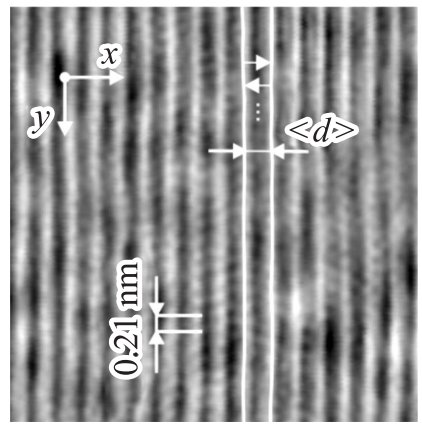

$b$
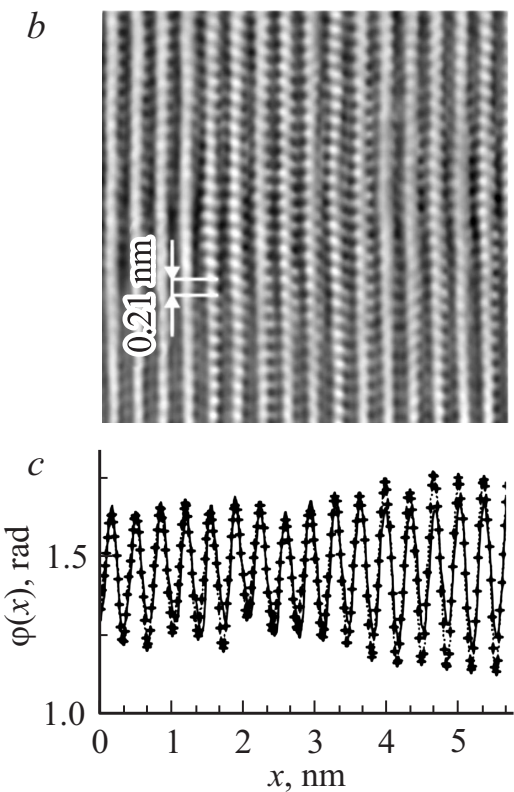

$d$

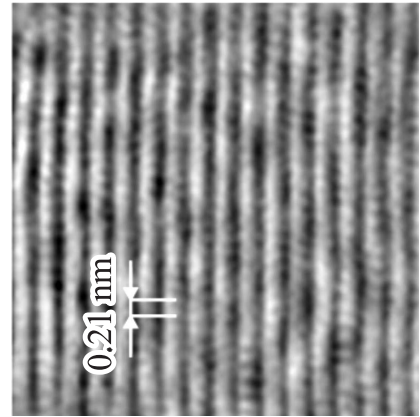

$e$
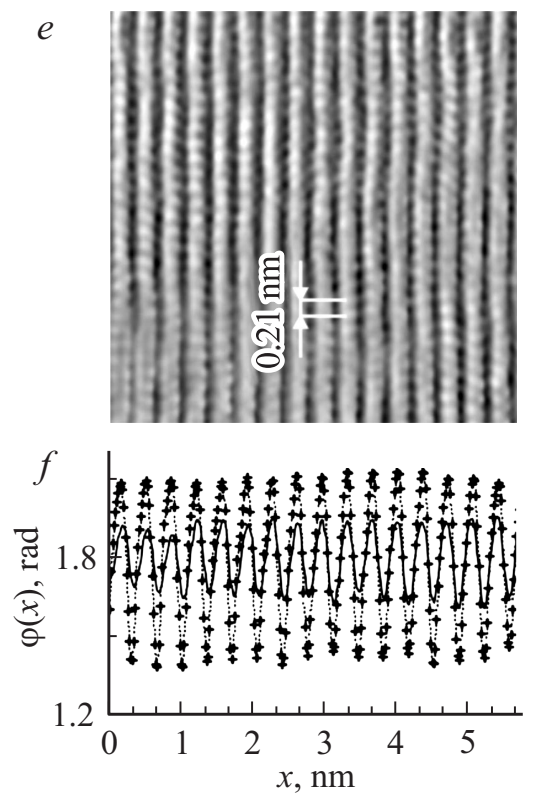

Рис. 2. Фазовые карты, полученные экспериментально для пироуглерода $(a)$ и углеситалла $(d)$, вычисленные для тестовых структур с обеднением базисных плоскостей атомами углерода на $3 \%(b)$ и $5 \%(e)$ и соответствующие усредненные одномерные распределения фазы $(c, f)$. Сплошные кривые на $c$ и $f$ соответствуют экспериментальным данным, а символьные кривые - расчетным распределениям. 
На рис. 2, $a, d$ приведены фазовые карты для пироуглерода и углеситалла, представляющие собой совокупности светлых и темных полос. Интенсивность светлых полос определяется спроецированными вдоль электронного пучка потенциалами атомов, расположенных в базисных плоскостях углеродной фазы. На некоторых из полос выявляются максимумы, соответствующие соседним атомным колонкам, которые находятся вдоль направления [100] на расстоянии $0.21 \mathrm{~nm}$ друг от друга. Одинаковые значения этого расстояния на рис. 2, a и $d$ свидетельствуют о корректной юстировке микроскопа при получении экспериментальных микрофотографий и дают основания для количественного сопоставления фазовых карт пироуглерода и углеситалла друг с другом. Размытость изображений базисных плоскостей и атомных колонок на фазовых картах указывает на то, что позиции атомов в углеродной фазе не являются строго регулярными, как в кристаллах. Такое расположение атомов является типичным для турбостратной фазы, для которой характерны как локальные искривления базисных плоскостей, так и их развороты относительно друг друга.

Вычисление среднего расстояния между базисными плоскостями проводилось в два этапа. Сначала на фазовых картах находились максимальные значения $\varphi(x, y)$, соответствующие центрам светлых полос, а затем последовательно локально определялись расстояния между центрами каждой пары соседних полос и полученные значения усреднялись. Положение центров полос предварительно оценивалось нахождением точек, в которых $\nabla \varphi(x, y)=0$ и которые соответствуют максимумам $\varphi(x, y)$. Используя эти точки, проводилось усреднение $\varphi(x, y)$ вдоль коротких участков светлых полос и полученный профиль аппроксимировался функцией Гаусса для прецизионного определения центров этих полос. После формирования таким образом линий, проходящих через максимумы $\varphi(x, y)$, каждая из них разбивалась на короткие прямолинейные отрезки, к которым строились перпендикуляры (рис. 2,a). Расстояние от основания такого перпендикуляра до точки пересечения с соседней линией определяло значения локального межплоскостного расстояния $d$. Множество значений $d$, вычисленных для всей фазовой карты, позволяло найти среднее значение межплоскостного расстояния $\langle d\rangle$. Используя описанную процедуру, было установлено, что среднее расстояние между базисными плоскостями в исследованных областях пироуглерода составляет $\left\langle d_{P y C}\right\rangle=0.343 \mathrm{~nm}$, а углеситалла $-\left\langle d_{P B C}\right\rangle=0.351 \mathrm{~nm}$.

Письма в ЖТФ, 2016, том 42, вып. 23 
Выявление факторов, влияющих на расстояние между базисными плоскостями, начиналось с формирования тестовых углеродных структур с применением метода МД. Первоначальные позиции атомов для МД-моделирования представляли собой систему параллельных электронному пучку базисных плоскостей, расположение которых соответствовало кристаллическому графиту с упаковкой типа $A B A B$. Разориентация направления [100] для этих плоскостей составляла угол $\theta=2.5^{\circ}$, как это показано на рис. $1, a$. Прямоугольная ячейка с атомами имела основание с размерами $a=b=10 \mathrm{~nm}$ (рис. $1, a)$. Длина ее третьего ребра, равная толщине образца, оценивалась на основе спектров энергетических потерь быстрых электронов [12] и составляла $c=24 \mathrm{~nm}$. Эволюция исходной атомной конфигурации и ее релаксация к состоянию равновесия осуществлялись в программном пакете LAMMPS с использованием межатомного потенциала взаимодействия AIREBO [13] и термостата Нозе-Гувера [14] с шагом по времени $0.5 \mathrm{fs}$. Процесс проводился при температуре $300 \mathrm{~K}$ в течение 100 ps.

Расчетные высокоразрешающие изображения вычислялись аналогично [10], влияние регистрирующей камеры микроскопа принималось во внимание в соответствии с [15]. Нахождение и нормировка распределения фазы волновой функции на основе этих изображений и последующее определение $\langle d\rangle$ для тестовых углеродных структур проводилось так же, как при анализе экспериментальных микрофотографий.

Для поиска атомных конфигураций, отвечающих экспериментальным данным, было выполнено две серии расчетов. В первой из них идеальные базисные плоскости случайным образом поворачивались относительно друг друга вокруг направления [001] на углы от $1^{\circ}$ до $5^{\circ}$. Для таких тестовых структур среднее межплоскостное расстояние оставалось практически неизменным и составляло $\langle d\rangle \approx 0.341 \mathrm{~nm}$, и, следовательно, одними разворотами базисных плоскостей нельзя объяснить экспериментально наблюдаемые изменения $\langle d\rangle$.

Во второй серии расчетов в исходные базисные плоскости вводились вакансии, т.е. осуществлялось их обеднение атомами углерода от 1 до 7\%. Результаты расчета свидетельствуют о том, что дефектность базисных плоскостей, обусловленная недостатком в них атомов углерода, оказывает существенное влияние на среднее значение $\langle d\rangle$ в тестовых структурах, приводя к его увеличению. Так, при обеднении базисных плоскостей атомами углерода на 3 и 5\% величины $\langle d\rangle$ становятся равными $\langle d\rangle \approx 0.343 \mathrm{~nm}$ и $\langle d\rangle \approx 0.352 \mathrm{~nm}$. Они близки к экспериментально полученным значениям $\langle d\rangle$ для пироуглерода и углеситалла

Письма в ЖТФ, 2016, том 42, вып. 23 
соответственно. Фазовые карты, представленные на рис. $2, b, e$, а также сравнение средних одномерных распределений фазы, приведенных на рис. 2, $c, f$, свидетельствует о хорошем соответствии найденных тестовых структур экспериментальным данным. Одна из причин большего обеднения атомами углерода базисных плоскостей в углеситалле может быть обусловлена тем, что атомы бора, встраивающиеся в углеродные сетки при их формировании, покидают свои позиции в процессе последующего выращивания материала и его охлаждения, способствуя росту частиц карбида бора, как это обсуждалось в [16].

Отметим, что при МД-моделировании тестовых структур возможное для углеситалла замещение углерода атомами бора, имеющего предел растворимости $2.35 \%$ при температуре роста $2350^{\circ} \mathrm{C}$ [17], во внимание не принималось. Оценки показывают, что такое замещение существенно слабее влияет на среднее межплоскостное расстояние $\langle d\rangle$, чем обеднение базисных плоскостей атомами углерода.

Таким образом, используя реконструкцию волновой функции электрона на основе дефокусной серии высокоразрешающих микрофотографий и последующую цифровую обработку двумерного распределения фазы этой функции, локально определены средние расстояния между базисными плоскостями в пироуглероде и в углеситалле, которые в исследованных областях оказались равными 0.343 и $0.351 \mathrm{~nm}$ соответственно. На основе моделирования тестовых структур методом молекулярной динамики и последующего получения расчетных распределений фазы волновой функции показано, что увеличение межплоскостных расстояний в пиролитических углеродных материалах по сравнению с графитом связано с обеднением базисных плоскостей атомами углерода на 3\% для исследованной области пироуглерода и на 5\% для углеситалла. Вместе с тем развороты базисных плоскостей относительно друг друга практически не влияют на расстояние между базисными плоскостями.

Работа выполнена при поддержке Министерства образования и науки РФ, проект № 2528.

\section{Список литературы}

[1] Delhaes P. // Carbon-based Solids and Materials. ISTE Ltd and John Wiley \& Sons, 2011. P. 591.

[2] Виргильев Ю.С., Татаринов В.Ф. // Химия твердого топлива. 2000. № 3. C. $57-63$.

Письма в ЖТФ, 2016, том 42, вып. 23 
[3] Oberlin A. // Carbon. 2002. V. 40. P. 7-24.

[4] Кукин В.Н., Боргардт Н.И., Агафонов А.В. и др. // Письма в ЖТФ. 2004. T. 30. B. 17. C. $76-82$.

[5] Bourat X., Trouvat B., Limousin G. et al. // J. Mater. Res. 2000. V. 15. N 1. P. $92-101$.

[6] Leyssale J.-M., Da Costa J.-P., Germain C. et al. // Carbon. 2012. V. 50. P. 43884400.

[7] Farbos B., Weisbecker P., Fischer H.E. et al. // Carbon. 2014. V. 80. P. 472-489.

[8] Böhlke T., Langhoff T.-A., Lin S. et al. // Z. Angew. Math. Mech. 2013. V. 93. N 5. P. 313-328.

[9] Prikhodko A.S., Borgardt N.I., Seibt M. // Phys. Stat. Sol. C. 2015. V. 12 . N 8. P. 1179-1182.

[10] Приходько А.С., Боргардт Н.И., Зайбт М. // Изв. РАН. Сер. физ. 2015. T. 79. № 11. C. 1536-1542.

[11] Allen L.J., McBride W., O'Leary N.L. et al. // Ultramicroscopy. 2004. V. 100. P. 91-104.

[12] Egerton R.F. // Electron Energy-Loss Spectroscopy in the Electron Microscope. N.Y.: Springer, 2011. P. 294.

[13] Stuart S.J., Tutein A.B., Harrison J.A. // J. Chem. Phys. 2000. V. 112. N 14. P. $6472-6486$.

[14] Hoover W.G. // Phys. Rev. A. 1985. V. 31. N 3. P. 1695-1697.

[15] Zou J.M. // Ultramicroscopy. 1996. V. 66. P. 21-33.

[16] Волков Р.Л., Боргардт Н.И., Кукин В.Н. и др. // Изв. РАН. Сер. физ. 2013. T. 77. № 8. C. 1076-1081.

[17] Lowell C.E. // J. Am. Ceram. Soc. 1967. V. 50. P. 142-144. 